\title{
Study of the Life Span of Adhesively Bonded Single Lap Joint Due to Creep
}

\author{
Ranulfo Martins Carneiro Neto ${ }^{1}$, Mila Siqueira de Paula ${ }^{2}$, \\ Eduardo Martins Sampaio ${ }^{2}$, Ney Robson Ferreira Rohem ${ }^{3}$, Lucas Lisbôa Vignoli ${ }^{1}$
}

\footnotetext{
${ }^{1}$ Center of Technology and Application of Composite Materials, Federal University of Rio de Janeiro - Department of Mechanical Enginnering, Aloísio da Silva Gomes Ave, 50, CEP: 27.930-560, Macaé, RJ, Brazil.

${ }^{2}$ Laboratory of Adhesion and Adherence, University of State of Rio de Janeiro - Department of Materials, Polytechnic Institute, Bonfim Ave, 25, CEP 28.625-570 - Nova Friburgo, RJ, Brazil.

${ }^{3}$ Federal Fluminense Institute - Department of Mechanics, Highway Amaral Peixoto, Km 164, Macaé - RJ, CEP 27.973-030, Macaé, RJ, Brazil.

e-mail: ranulfocarneiro@yahoo.com.br, 1l.vignoli@mecanica.coppe.ufrj.br, millasiqueira85@gmail.com; edu.msampaio@gmail.com,neyrohem@gmail.com
}

\begin{abstract}
Adhesive joints are often used in several areas, including offshore systems and automobiles. The development of suitable models to predict the joint behavior has several challenges, especially due to creep phenomena. The aim of this study is to investigate the creep lifetime of single lap joints considering two different adhesives (epoxy and polyurethane). Long-term tests are performed using a pneumatic creep equipment (PCE). The parameters to the creep model are obtained for each adhesive, where load and life span are related. The models obtained and the times of joints life span are compared with two other adhesives previously studied. The results confirm that the knowledge of the lap shear strength value is just a reference to the designer, however experimental tests in creep for each different adhesive is necessary. The comparison between the joints bonded with two different epoxies shows similar results, what was demonstrated by the similar curves obtained by the models. The comparison between polyurethane adhesives did not show similar behavior in the curves obtained from the models, especially in the time of life span.
\end{abstract}

Keywords: Creep, single lap joints, life span, bonded joint.

\section{INTRODUCTION}

Structural adhesives have been used in several areas in recent years, including civil, automotive and oil and gas. Some advantages of bonded joints applications include the capability in joining dissimilar materials, structures with reduced weight, reduction of stress concentration and fast execution [1, 2]. Despite some recent advances in fatigue [3] and fracture [4] modeling of bonded joints adhesives usually present time-dependent stress behavior under static mechanical loading conditions [5], which means that the mechanical properties change over time. For this reason, creep phenomenon must be investigated experimentally aiming to correctly predict the joint behavior until the failure, although there is great difficult due to low productivity of results, since common test machine only work with one specimen per time.

Creep can be defined as the permanent deformation dependent on time of materials when submitted to a constant load [6], which is generally referred as creep or retardation [5]. Already under static strain condition the creep is referred as relaxation, which can occur in a joint with a confined construction [5]. The creep curve progression can be divided into three phases: primary, secondary and tertiary. At the beginning of the creep test an instantaneous strain occurs, consequence of the instantaneous load (dead load) that rapidly varies from zero to the creep load required. So, the primary creep takes place and a high rate of strain over time occurs. This strain rate 
decreases until the creep stabilizes. This stabilization indicates the secondary creep, where a constant creep speed is observed. Finally, a considerable increase at the strain rate occurs until the material failure [5].

The adhesives can exhibit viscoelastic and viscoplastic behavior when relatively high temperature and high stress levels occurs [7]. If the yield strength is not required to initiate viscous flow, the viscoelastic models can be used. The classic viscoelastic models include: i) Maxwell model - spring in series with a viscous dashpot; ii) KelvinVoigt model - parallel connection of a spring and a dashpot; iii) Burger model - Kelvin-Voigt and Maxwell models in series [5, 7]; and iv) Zener model - parallel association between one spring and the dashpot spring assembly [8]. A reduction of durability may occur due to rheological phenomena, which are described in the cited models. The work of MAJDA et al. [9] investigated four levels of constant stress at ambient temperature in an epoxy adhesive. Considering the parameters of Burgers model, the authors observed that they are considerably affected by the stress level. Thus, a modified Burgers model was proposed considering a non-Newton viscosity for the dashpots and a nonlinear spring in the Kelvin-Voigt element. ZEHSAZ et al. [10] presented experimental results of uniaxial creep tests in an epoxy adhesive that have nonlinear viscoelastic behavior. The authors proposed a creep constitutive model to simulate creep in different stresses and temperatures. The proposed rheological model is composed by one Maxwell and two Zener models. The creep behavior was also evaluated by two classic models: Bailey-Norton equation and generalized time-hardening. The time-hardening model results presented better consistency than Bailey-Norton model, considering the experimental data achieved in different stress and temperature levels. However, the best agreement between experimental data and calculated values was obtained by the proposed model (one Maxwell and two Zener models). COSTA et al. [11] also studied the creep behavior in epoxy adhesives. The work investigated the effect of creep in the Young's modulus after $1000 \mathrm{~h}$ of loading. Furthermore, the time between the reception of adhesive and the mixture of components was also considered. In general, the values of Young's modulus did not change greatly. Additionally, the creep experiments concluded that the adhesive used can be assumed as linear viscoelastic / viscoplastic since the sustained stress level is $60 \%$ of the adhesive's tensile strength. The modified Burgers model proposed by FENG [12] was applied in that work and exhibited good agreement with the experimental results. SAHELLIE et al. [13] investigated the shear creep behavior of double lap galvanized steel joints using an epoxy adhesive. The specimens were subjected to different sustained loads for up to 3.5 months. The experimental results confirmed that creep behavior is dependent on the magnitude of the applied stress. Besides that, the authors modelled the creep using the viscoelastic models of Findley and Burger, concluding that Burger's model should be used to predict longer lifetime.

There are other published works that also investigated creep considering numerical models. The work of ZEHSAZ et al. [14] performed experiments in adhesive bulk specimens to obtain the necessary parameters to the creep constitutive equations. This way, a numerical analysis using finite element method in single lap joints (SLJ) was carried out. The numerical results showed that due to the creep straining, there is a strain accumulation in the SLJ corners. Increasing layer thickness and using fillet joint were proposed to improve structural response. SADIGH [15] investigated numerically and experimentally the creep strain in double lap joints considering four different temperatures. A model to describe creep strain was proposed and implemented in Abaqus software. The results showed that finite element solution can simulate the creep strain with good accuracy at different stress and temperature levels. Both works $[14,15]$ did not calculate or estimate the life span of the joints.

The standards to determine the time to rupture of bonded joints under static load are defined in ISO 15109 [16]. KHALILI et al. [17] investigated the creep behavior of fiber reinforced adhesive joints using three types of fibres (carbon, e-glass and aramid). The creep tests lasted about 2.7 hours and the results showed that it is recommended to add fibres in the bondline because they improve some joints mechanical properties. Additionally, the largest failure time occurred to the carbon reinforced fibre orientation of $\pm 45^{\circ}$. The long-term behavior of epoxy adhesive in double shear test was investigated by MESHGIN et al. [18], using the concrete-FRP interfaces. The experimental work lasted 9 months and showed that shear creep behavior of epoxy applied in this hybrid joint is dependent of time before loading and the ratio of magnitude of shear stress and the ultimate shear strength. HUN $e t$ al. [19] investigated the strength degradation of adhesive joints after long term exposure to a combined mechanicalhygro-thermal environment, which is also a way to investigate creep. The experiments performed in SLJ showed that the existence of water degraded the joint strength. Additionally, the introduction of sustained load further extended this effect, although not so significantly. QUEIROZ et al. [6] performed long term tests to investigate the creep in SLJ with two different adhesives (epoxy and polyurethane) in room temperature. The authors evaluated the creep behavior of bonded joints as function of the applied load. The percentual of creep load ranged from 58\% to 97\% of the average lap shear strength $\left(\tau_{u}\right)$. The SLJ bonded with epoxy adhesive supported more than 1700 hours with load of $70 \%$ of $\tau_{u}$ and more than 2300 hours with load equal to $60 \%$ of $\tau_{u}$. Already SLJ bonded with polyurethane 
adhesive supported about 670 hours with load equal to $58 \%$ of $\tau_{u}$. Thus, epoxy exhibited a higher creep resistance than polyurethane adhesive.

Studies to verify if there is a tendency of creep in bonded joints regarding the failure time and percentage of $\tau_{u}$ that leads the joint to a long time without failure for both epoxy and polyurethane adhesives are not found in literature. In order to fill this gap this work aims to evaluate the life span of SLJ when submitted to creep (dead load). Two adhesives are used to join the metallic substrates, one with epoxy base (NVT 201E) and other with polyurethane base (masterpur 300). The parameters to the creep model are obtained for each adhesive, where load and life span are related. The main contribution of this work is to investigate the creep behavior of two adhesives (NVT 201E and masterpur 300), especially the times until failure, which analysis is rare in literature. Considering experimental results obtained in this work and also in previous works, both the creep response between adhesives with the same base and with different bases were evaluated, which is the main novelty of this work. It is important in order to check the sensibility of creep behavior in adhesives similar or not, which can be useful to designers when choosing the adhesive.

\section{MATERIALS AND METHODS}

The tests to obtain the average lap shear strength $\left(\tau_{u}\right)$ for both adhesives used were performed in a Universal Shimadzu Tensile Machine model Autograph AG-X Plus 100KN, according ASTM D1002 [20] with cross head speed of $1.3 \mathrm{~mm} / \mathrm{min}$. This is an essential part of this study because $\tau_{u}$ is the reference value to apply the sustained load in creep tests.

The adherent material used in SLJ was carbon steel A36, where the plates have thickness of $1.6 \mathrm{~mm}$ (Fig. 1) and width of $25.5 \mathrm{~mm}$ (not showed). Spacers were inserted at both ends of the SLJ during loading process, aiming to avoid eccentricity. After cutting the plates, a mechanical treatment consisting of surface G40 grit blasting was performed, followed by the silane application, which aims to promote a better adhesion between the A36 plates and the adhesives. The A36 plate surface morphologies were measured by a three-dimensional rugosimeter TalyScan with inductive tip - Taylor Hobson. The rugosity was measured in two steps: after grit blasting process and after silane application, being considered two parameters: $R_{t}$ - corresponding the distances between the peaks and the valleys and $R_{a}$ - corresponding to the average rugosity. For all measures a speed of $100 \mu \mathrm{m} / \mathrm{s}$, mesh precision $x y-1 \times 10(\mu \mathrm{m})$ and measurement areas of $4 \mathrm{~mm} x 1 \mathrm{~mm}$, following the ISO 4288:1996 [21] recommendations.

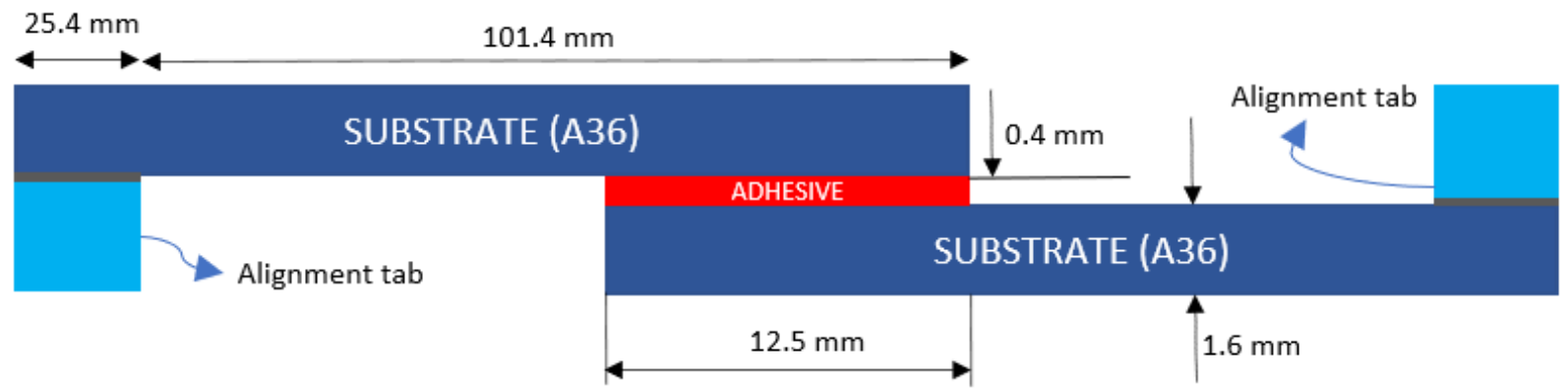

Figure 1: Dimensions of single lap joints for both adhesives used in this work (epoxy and polyurethane).

The adhesive with epoxy base is the NVT 201E, which is a structural adhesive and has been used in pipe repairs successfully, as can be seen in the references [22, 23]. Additionally, NVT 201E can be also applied in surface leveler, filling of worn parts and coating. The adhesive with polyurethane base is the masterpur 300 . Usually, these types of adhesives are more ductile than an epoxy and can be used for bonding plastics, wood and metals [4]. Handling time is relatively short, thus, the application by a mechanized system is ideal, although its manual use is also possible. For both adhesives the thickness was $0.4 \mathrm{~mm}$ (Fig. 1) and the cure time was 24 hours at room temperature. Some information about both adhesives provided by the manufacturers are shown in Table 1. 
Table 1: Technical information of adhesives with epoxy and polyurethane bases.

\begin{tabular}{lcc}
\hline Description & $\begin{array}{c}\text { Epoxy adhesive - } \\
\text { NVT 201E }\end{array}$ & $\begin{array}{c}\text { Polyurethane adhesive - } \\
\text { Masterpur 300 }\end{array}$ \\
\hline Time application & $35 \min \left(25^{\circ} \mathrm{C}\right)$ & $5 \mathrm{~min}\left(25^{\circ} \mathrm{C}\right)$ \\
Density & $1.24 \mathrm{~g} / \mathrm{cm}^{3}$ & $1.16 \mathrm{~g} / \mathrm{cm}^{3}$ \\
Rockwell hardness Shore D (ASTM D2240) & 60.0 & 80.0 \\
Mixing ratio (mass) - Components A and B & $100: 43$ & $1: 4$ \\
Curing time & $24 \mathrm{~h}$ & $24 \mathrm{~h}$ \\
\hline
\end{tabular}

The bonding process occurred at room temperature and controlled moisture. A template was used to bond the joints aiming to guarantee the adhesive thickness $(0.4 \mathrm{~mm})$. A primer was used in the bonding process with | masterpur 300 adhesive. A total of ten SLJ specimens were manufactured to obtain average lap shear strength $\left(\tau_{u}\right)$, five for each type of adhesive.

The specimens to the creep tests were manufactured by the same way of above related. At least four specimens were tested for each percentage of $\tau_{u}$. The pneumatic creep equipment (PCE) was used to perform the creep tests, which has capability to test 10 independent specimens, measuring the time until rupture of each one separately. The operation of PCE is described in detail in the reference [6]. The creep model applied to the two SLJ groups (epoxy and polyurethane adhesive) is presented in Eq. (1).

$$
\sigma=k t^{n}
$$

where $\sigma$ is the load applied (stress), $t$ is the time until failure, $k$ and $n$ are the parameters to be obtained by linear regression using the Levenberg Marquardt method.

The model presented in Eq. 1 was also used by QUEIROZ et al. [6]. This model aims to estimate the joints lifetime; thus, it should not be used to predict the strain behavior. It has as advantage the possibility to calculate the lifetime of bonded joints by a simple equation, even in creep loads that were not tested experimentally. Of course, this calculation must be done carefully, as the time obtained is an estimative based on previous experimental results at different loads considering an exponential function.

\section{RESULTS AND DISCUSSION}

\subsection{Analysis of Rugosities}

The results of the rugosities in the metal plates post silane application had a little decrease when compared to post surface treatment, as can be seen in Table 2. The parameter $R_{t}$ and $R_{a}$ decreased $1 \%$ and $4.4 \%$, respectively, which shows that silane application did not have a significant influence in the plate rugosities. Anyway, this small decrease was expected because silane application can create micro rugosities that contribute to increase the material strength.

Table 2: Rugosities analysis before and after silanization.

\begin{tabular}{ccccc}
\hline \multirow{2}{*}{ Description } & \multicolumn{2}{c}{ Post surface treatment } & \multicolumn{2}{c}{ Post silane application } \\
& $\mathbf{R a}(\boldsymbol{\mu m})$ & $\mathbf{R t}(\boldsymbol{\mu m})$ & $\mathbf{R a}(\boldsymbol{\mu m})$ & $\mathbf{R t}(\boldsymbol{\mu m})$ \\
\hline Average & 11.7 & 87 & 11.60 & 83.200 \\
Standard deviation $(\%)$ & 11.9 & 11.6 & 9.6 & 7.30 \\
\hline
\end{tabular}

\subsection{Lap Shear Strength of Single Lap Joints}

The tests in SLJ with epoxy adhesive (NVT 201E) presented good repeatability, both in stress and in strain (Fig. 2). The average value followed by the standard deviation was $\tau_{u e}=17.9 \pm 0.4(\mathrm{MPa})$. To the joints with masterpur 
300 adhesive a good repeatability was also obtained (Fig. 3), being the average value followed by the standard deviation $\tau_{u p}=4.6 \pm 0.3(M P a)$, as expected, considerably smaller than epoxy.

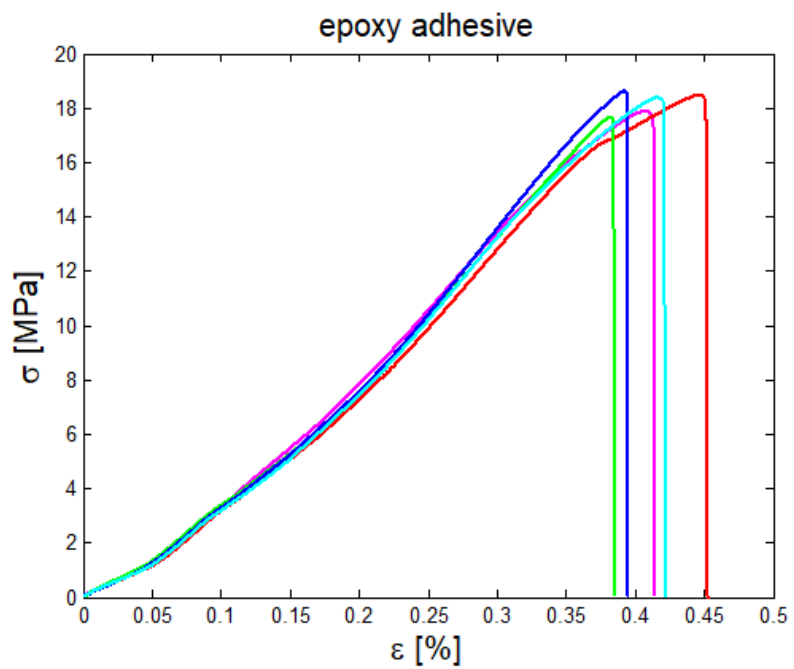

Figure 2: Graph of stress versus strain in SLJ bonded with epoxy adhesive.

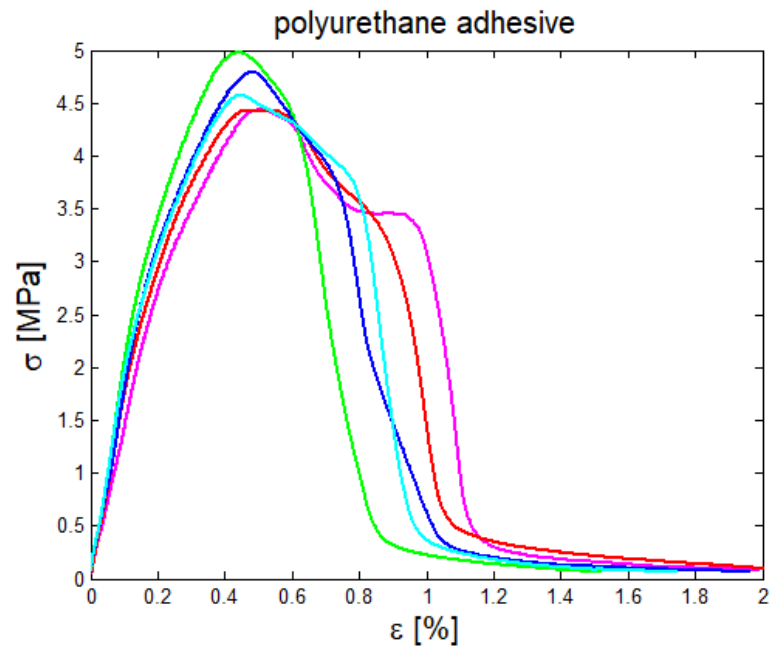

Figure 3: Graph of stress versus strain in SLJ bonded with polyurethane adhesive.

\subsection{Creep Tests with NVT 201E and Masterpur 300}

The creep tests were done considering some percentual values of $\tau_{u}$. A minimum of 4 samples were used for each of the load levels, being all the tests carried out at room temperature. 
Table 3: Results of creep testing for epoxy adhesive NVT 201E.

\begin{tabular}{ccccc}
\hline $\begin{array}{c}\text { Strength percentage of lap } \\
\text { shear strength }\end{array}$ & $\begin{array}{c}\text { Strength in PCE } \\
\text { (MPa) }\end{array}$ & $\begin{array}{c}\text { Number of } \\
\text { specimens }\end{array}$ & \multicolumn{2}{c}{ Time until rupture (hours) } \\
\cline { 5 - 5 } Average & Standard deviation \\
\hline $100.0 \%$ & 17.9 & 10 & 0.1 & 0.003 \\
$68.4 \%$ & 12.2 & 9 & 1.9 & 1.35 \\
$59.5 \%$ & 10.7 & 10 & 69.9 & 33.41 \\
$49.6 \%$ & 8.9 & 4 & 2000.0 & NA \\
$45.6 \%$ & 8.2 & 10 & 1300.0 & NA \\
$39.7 \%$ & 7.1 & 10 & 1300.0 & NA \\
\hline
\end{tabular}

\subsubsection{Epoxy Adhesive - NVT 201E}

The Table 3 shows the time until rupture for each percentual of $\tau_{u e}$ considered. The joints tested with $39.7 \%$ and $45.6 \%$ of $\tau_{u e}$ were removed after $1300 \mathrm{~h}$ without failure. These latter joints $\left(45.6 \%\right.$ of $\tau_{u e}$ ) were again loaded, however with a greater strength value $\left(8.9 \mathrm{MPa}-49.6 \%\right.$ of $\left.\tau_{u e}\right)$, which were also removed without failure after 2000 h.

Considering the three first group tested (59.5 to $100 \%$ of $\tau_{u e}$ ) high standards deviation occurred, which is common in similar creep tests. An expressive increase in SLJ life span was observed from the tension value 10.7 $\mathrm{MPa}$ to $8.9 \mathrm{MPa}$, going from 69.9 to more than $2000 \mathrm{~h}$. It shows the importance of long-term creep tests and reinforces the difficulty to predict the bonded joint behavior. In this case, a difference of $1.8 \mathrm{MPa}\left(10 \%\right.$ of $\left.\tau_{u e}\right)$ in the creep load leads to a large difference in joint life span.
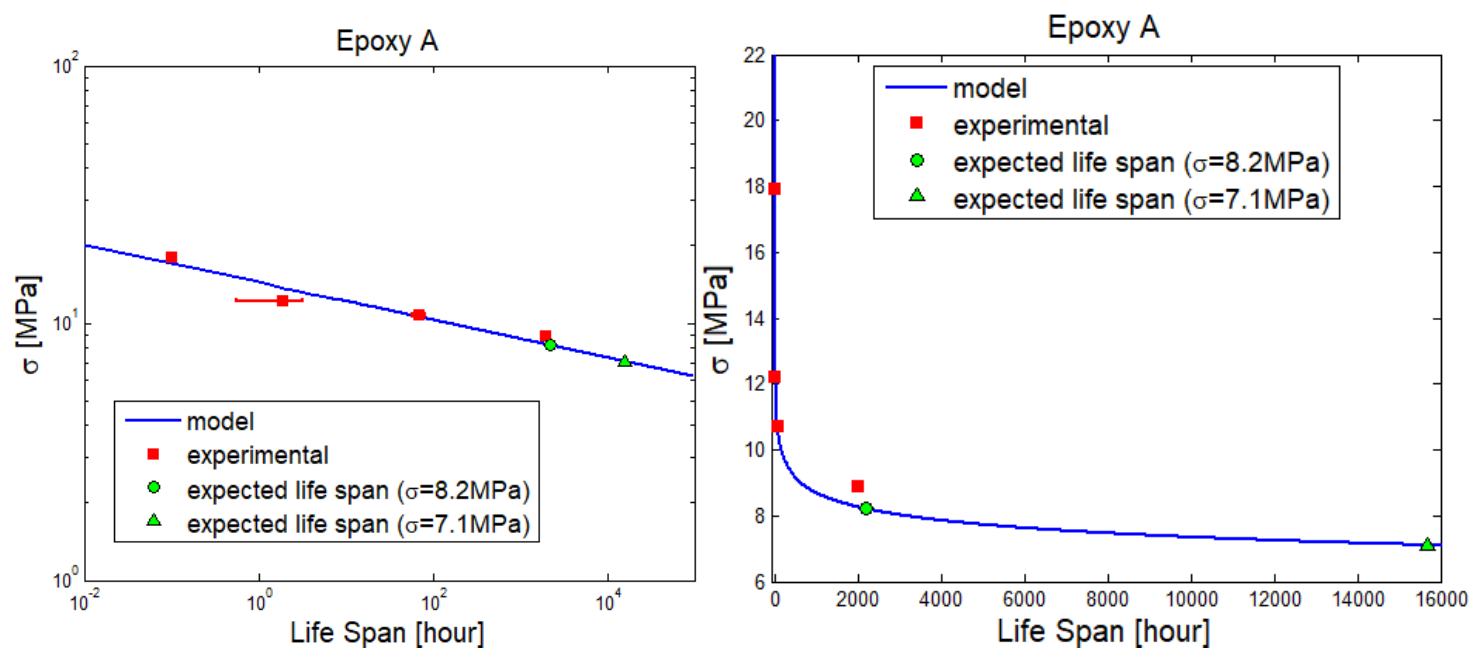

Figure 4: Graphs showing the creep model curve and experimental data for SLJ bonded with epoxy adhesive. a) Logarithmic scale, b) cartesian scale.

The parameters of creep model (Eq. 1) were calculated by regression linear, as described in Section 2. The data considered did not include the last two rows of the table, which is necessary to maintain the data consistency, i.e., lower load values lead to greater failure time. The constant values found were: $k_{1}=14.408(\mathrm{MPa})$ and $n_{1}=-0.0732$. The graphs in cartesian and logarithimic scales are shown in Fig. 4. The graph with logarithmic scale shows a tendency to the experimental data alignment (straight line). The model proposed had a satisfactory approximation with the experimental data. In the graph from Fig. 4 the two points highlighted in green related to the time life span of that tensions from the two last rows of table 3 (8.2 and 7.1MPa), being the values $2197 \mathrm{~h}$ and $15700 h$, respectively. In both cases the tests were interrupted without failure after $1300 \mathrm{~h}$. 
Table 4: Results of creep testing for polyurethane adhesive masterpur 300.

\begin{tabular}{lllll}
\hline $\begin{array}{l}\text { Strength } \\
\text { percentage of } \\
\text { tensile } \\
\text { strength }\end{array}$ & $\begin{array}{l}\text { Strength } \\
\text { in PCE } \\
\text { (MPa) }\end{array}$ & $\begin{array}{l}\text { Number of } \\
\text { specimens }\end{array}$ & Average & $\begin{array}{l}\text { Standard } \\
\text { deviation }\end{array}$ \\
\hline $100.0 \%$ & 4.6 & 5 & 0.02 & 0.001 \\
$81.8 \%$ & 3.8 & 5 & 9.7 & 10.56 \\
$70.6 \%$ & 3.2 & 5 & 12.3 & 7.79 \\
$57.3 \%$ & 2.6 & 5 & 14.2 & 7.97 \\
$46.7 \%$ & 2.1 & 5 & 20.5 & 9.88 \\
\hline
\end{tabular}

\subsubsection{Polyurethane Adhesive - Masterpur $\mathbf{3 0 0}$}

The time until rupture for each percentual of $\tau_{u p}$ considered is shown in table 4 . The standard deviation (percentage) decreased as the strength in PCE decreased, what was expected.

| The life span of SLJ bonded with masterpur 300 were low. Even to small percentages of $\tau_{u p}$ the time to failure did not exceed 21 hours.

Considering the data from table 4 (strength and time until rupture), except the first line, the parameters of creep model (Eq. 1) were calculated by regression linear. The values found were: $k_{2}=25.21(M P a)$ and $n_{2}=$ -0.834 . The graphs in cartesian and logarithmic scales are shown in Fig. 5. The first experimental data $\left(100 \% \tau_{u p}\right)$ is not showed in the graph because this would drastically change the graphic arrangement presented. Anyway, it is important to note that this was the only point that stayed distant from the curve generated by the model, which does not imply in troubles since this is a region of very little interest.
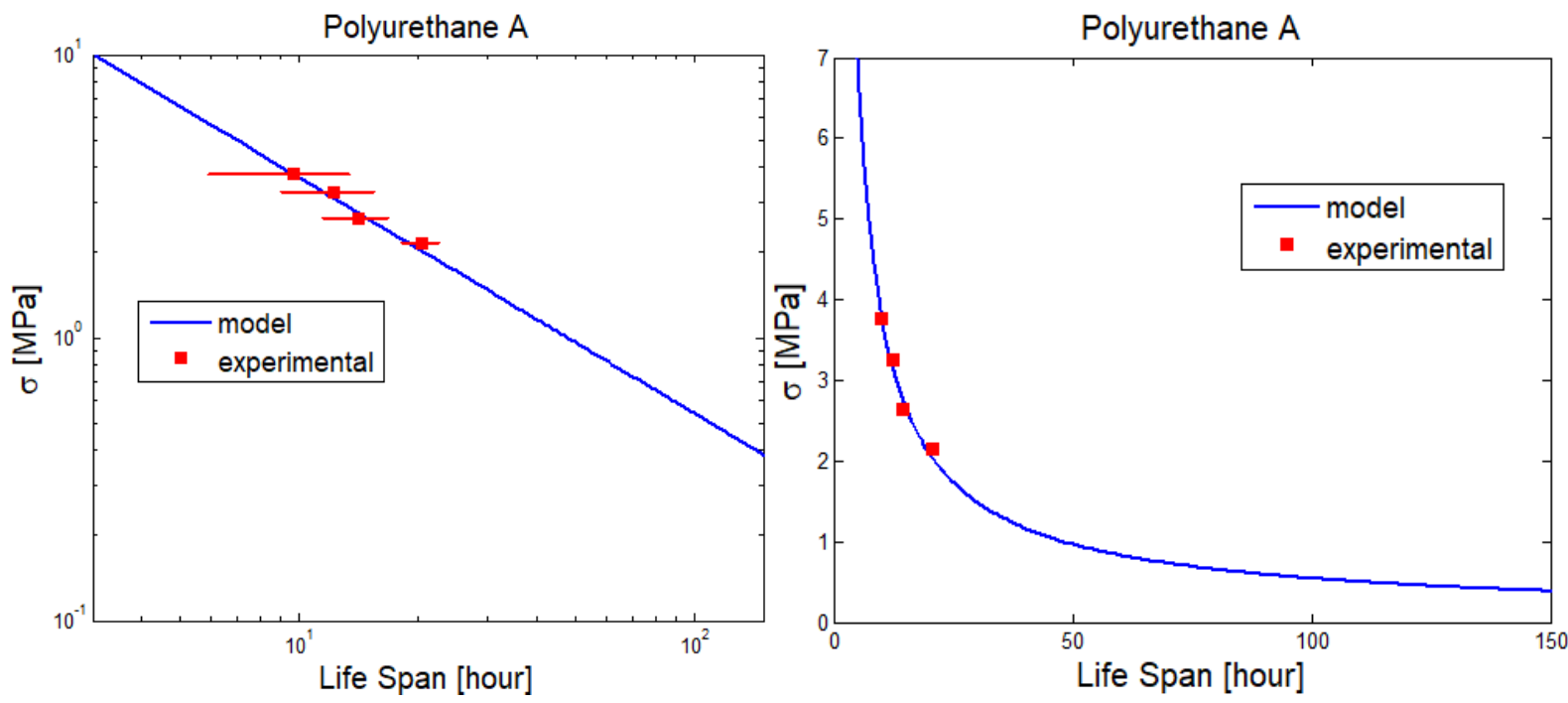

Figure 5: Graphs showing the creep model curve and experimental data for SLJ bonded with polyurethane adhesive. a) Logarithmic scale, b) cartesian scale.

\subsubsection{Comparison Between Similar Adhesives}

This section aims to verify if there is a tendency in the joint behavior submitted to creep considering similar adhesives. Those adhesives used in this work will be called by epoxy A (NVT 201E) and poly A (masterpur 300), already the adhesives used in reference [6] will be called by epoxy B and poly B. 

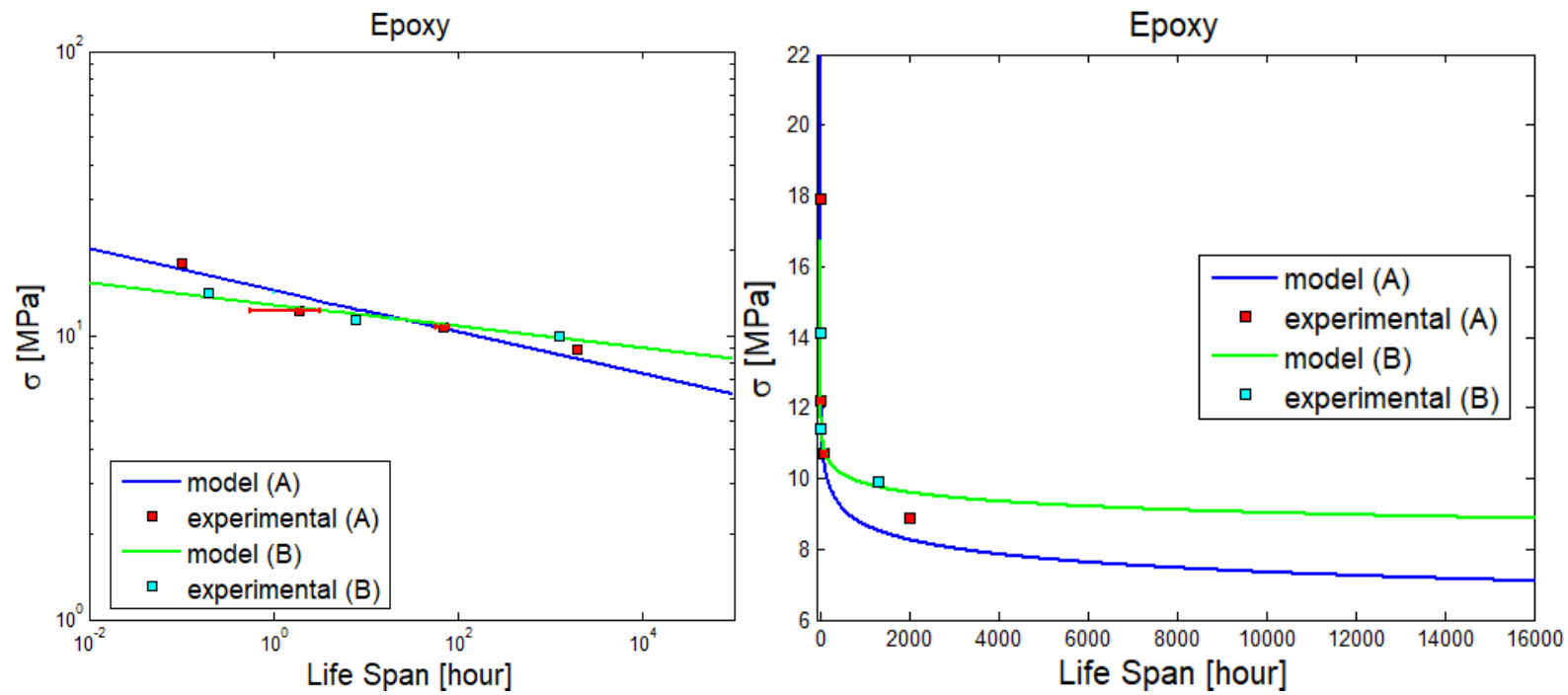

Figure 6: Graphs showing the creep models and experimental data for epoxy adhesives A and B. a) Logarithmic scale, b) cartesian scale.

The comparison graphs of epoxy adhesives are shown in Fig. 6, where are represented the model and experimental values obtained for both adhesives (epoxy A and B) in cartesian and logarithmic scales. The model from epoxy B used three experimental data and the epoxy A used four. From Fig. 6 a) (logarithmic scale) is possible to see that before the straight lines coincide, the joints bonded with epoxy A leads to a longer failure time, i.e., considering the same strength, epoxy A has a longer life span than epoxy B. After the coincident point, epoxy B has a longer life span. In general, the results show that epoxy B is more resistant to creep than epoxy A. This may be related to the largest Young's modulus of epoxy B, although epoxy A has largest lap shear strength in SLJ (table 5). Considering a life span of $1000 \mathrm{~h}$, the epoxy A model predicted a tension of $8.7 \mathrm{MPa}$ while epoxy B model predicted $9.9 \mathrm{MPa}(13.8 \%$ largest). For a life span of $30000 \mathrm{~h}$ the tension predicted by epoxy B was $27.9 \%$ largest than epoxy A model.

Table 5: Comparison between epoxy adhesives A and B.

\begin{tabular}{lccc}
\hline Description & Epoxy A & Epoxy B & $\begin{array}{c}\text { Difference \% } \\
\text { |(A-B)/B }\end{array}$ \\
\hline Lap shear strength (SLJ) & $17.9 \pm 0.4 \mathrm{MPa}$ & $14.6 \pm 0.4 \mathrm{MPa}$ & $22.6 \%$ \\
Young's modulus & $2090 \mathrm{MPa}$ & $14000 \mathrm{MPa}$ & $85.1 \%$ \\
Predict tension to life span 1000 hours & $8.7 \mathrm{MPa}$ & $9.9 \mathrm{MPa}$ & $12.1 \%$ \\
Predict tension to life span 10000 hours & $7.3 \mathrm{MPa}$ & $9.0 \mathrm{MPa}$ & $18.9 \%$ \\
Predict tension to life span 30000 hours & $6.8 \mathrm{MPa}$ & $8.7 \mathrm{MPa}$ & $21.8 \%$ \\
\hline
\end{tabular}

Fig. 7 shows the comparison graphs of polyurethanes adhesives, being represented in cartesian and logarithmic scales. The graphs show that poly B is clearly more resistant to creep than poly A. The curves are not close to each other, thus, a similar behavior and life span of poly A and B was not verified. This large difference in life span may have occurred due to the largest Young's modulus and lap shear strength in SLJ of poly B (table 6). Considering a life span of $500 \mathrm{~h}$, the model from poly A predicted a tension of only $0.14 \mathrm{MPa}$ while poly B model predicted 6.75 $\mathrm{MPa}$ (much larger), although it is still a low value. For a life span of $10000 \mathrm{~h}$ the tension predicted by poly B was also considerably largest than poly A model. It indicates that poly A should not be applied in creep. Already poly B presented better results, which suggest its application in creep conditions provided that the tension limits are observed. 

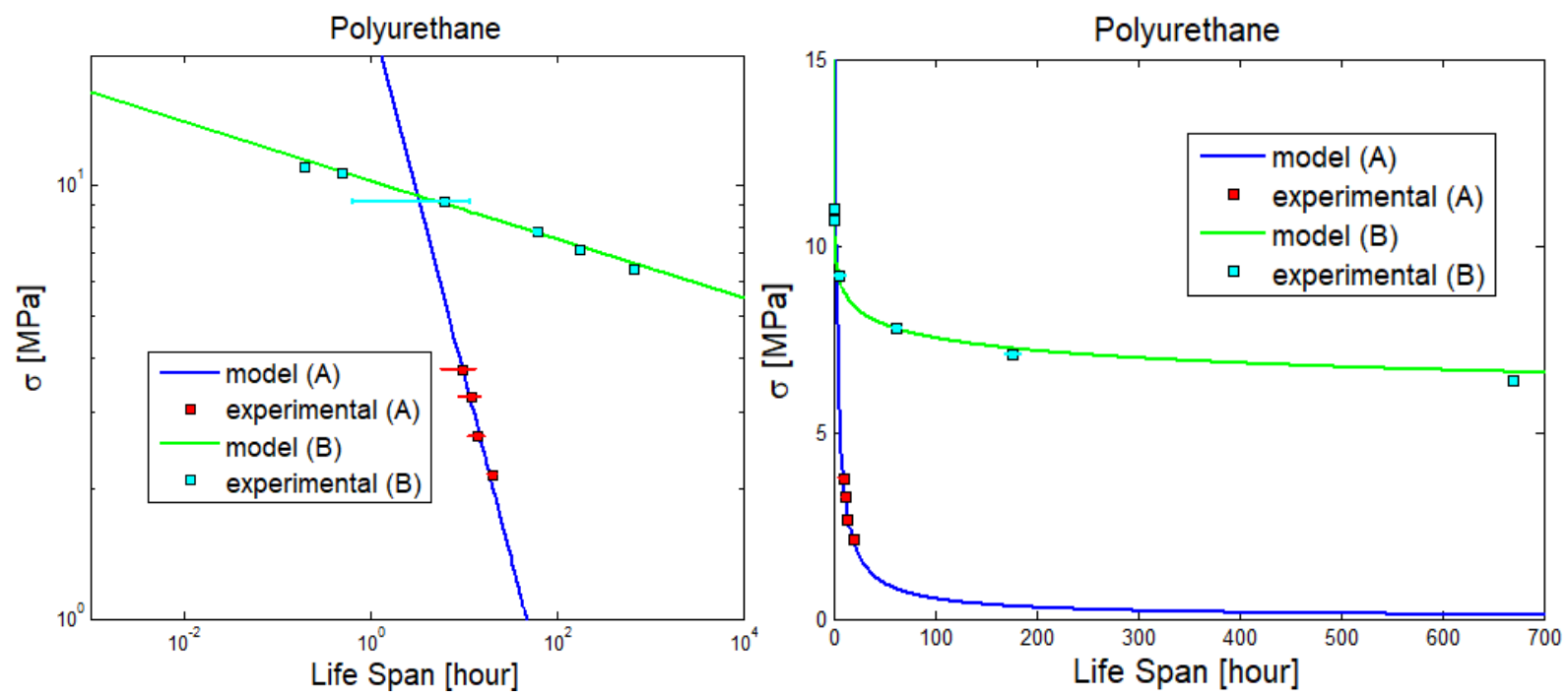

Figure 7: Graphs showing the creep models and experimental data for polyurethane adhesives A and B. a) Logarithmic scale, b) cartesian scale.

Table 6: Comparison between polyurethane adhesives A and B.

\begin{tabular}{lccc}
\hline Description & Poly A & Poly B & $\begin{array}{c}\text { Difference \% } \\
|(\mathbf{B}-\mathbf{A}) / \mathbf{A}|\end{array}$ \\
\hline Lap shear strength (SLJ) & $4.6 \pm 0.3 \mathrm{MPa}$ & $11.0 \pm 3.9 \mathrm{MPa}$ & $139.1 \%$ \\
Young's modulus & $90 \mathrm{MPa}$ & $880 \mathrm{MPa}$ & $877.8 \%$ \\
Predict tension to life span 500 hours & $0.14 \mathrm{MPa}$ & $6.75 \mathrm{MPa}$ & $4721.4 \%$ \\
Predict tension to life span 1000 hours & $0.08 \mathrm{MPa}$ & $6.44 \mathrm{MPa}$ & $7950.0 \%$ \\
\hline
\end{tabular}

\section{CONCLUSIONS}

The life span of SLJ submitted to creep on retardation were evaluated in two types of adhesives, one epoxy and one polyurethane. In this first step, the experimental results showed that epoxy adhesive is considerably more resistant to creep than polyurethane one. In both cases, through the experimental results, the parameters of an existing model were obtained, this way, the life span of SLJ for different loads could be estimated. A good agreement between the experimental values and the models proposed was reached. Additionally, the results confirmed that the knowledge of the average lap shear strength is just a reference to the designer, however, experimental tests in creep for each different adhesive is necessary to adequately predict the joints behavior.

The second step consisted to evaluate the creep in SLJ bonded with similar adhesives (same base). Therefore, a comparison between two epoxies and two polyurethanes adhesives were performed, in each case considering one adhesive study in this work and another from existing literature. The results of epoxy adhesives showed similar results, what was demonstrated by the similar curves obtained by the models. For the same load, epoxy B presented largest life span than epoxy A, although the latter one also reached acceptable results in creep tests. The comparison between polyurethane adhesives did not show similar behavior in the curves obtained from the models, especially in the time of life span. The poly B adhesive presented considerably largest life span than poly A, latter one presenting very small strength values to resist the creep for $1000 \mathrm{~h}$. This way, poly A is not recommended to be applied in situations where there is a predicted creep condition. It is important to note that the parameters of the models are only valid for the tested conditions. If different adhesives, substrates or joints are applied, new parameters must be calculated based on new experimental results obtained at that new conditions.

Further work is needed to test other adhesives with epoxy and polyurethane bases aiming to check if the creep behavior is related to mechanical properties and also if other epoxy adhesives have similar behavior of those presented in this work. 


\section{ACKNOWLEDGEMENTS}

The authors would like to thank the Laboratory of Adhesion and Adherence for financial support.

\section{BIBLIOGRAPHY}

[1] CARNEIRO NETO, R.M., SAMPAIO, E.M., ASSIS, J.T., Numerical and experimental analysis of bonded joints with combined loading, DOI 10.1016/j.ijadhadh.2019.02.002. International Journal of Adhesion \& Adhesive, v. 90, pp. 61-70, 2019.

[2] PESSANHA, M.C.R., DIAS, D.P., FILGUEIRA, M., et al., Uniaxial tensile tests with temperature variation in adhesive used in bonded joints of GFRP pipes applied in offshore platforms, https://doi.org/10.1590/S151770762008000100023. Revista Matéria, v. 13, n. 1, 2008.

[3] MARCHEZIN, E., PARDINI, L.C., GUIMARÃES, V.A., Avaliação do comportamento em fadiga de juntas estruturais de ligas de Al2024T3 coladas com adesivo epóxi, Revista https://doi.org/10.1590/S151770762012000100002. Matéria, v. 17, n. 1, 2012.

[4] ALVES, J.S., KENEDI, P.P., BARROS, S., Evaluation of structural adhesive joints fracture toughness without crack measurement, Revista Matéria, v. 26, n. 1, 2021.

[5] DA SILVA, L.F.M., OCHSNER, A., ADAMS, R.D. (eds), Handbook of Adhesion Technology, https://doi.org/10.1007/978-3-319-55411-2. Springer-Verlag Berlin Haidelberg, 2011.

[6] QUEIROZ, R.A., SAMPAIO, E.M., CORTINES, V.J., et al., Study on the creep behavior of bonded metallic joints, DOI 10.1186/2196-4351-2-8. Applied Adhesion Science, 2:8, 2014.

[7] DILLARD, D.A. Advances in Structural Adhesive Bonding, https://doi.org/10.1016/B978-1-84569-435-7.500213. Woodhead Publishing Limited, 2010.

[8] SAULNIER, F., ONDARÇUHU, T., ARADIAN, A., et al., Adhesion between a Viscoelastic Material and a Solid Surface, DOI: https://doi.org/10.1021/ma021759t Macromolecule, 2004.

[9] MAJDA, P., SKRODZEWICZ, J., A modified creep model of epoxy adhesive at ambient temperature, International Journal of Adhesion \& Adhesives, v. 29, pp. 396-404, 2009.

[10] ZEHSAZ, M., VAKILI-TAHAMI, F., SADIGH, M.A.S., Modified creep constitutive equation for an epoxybased adhesive with nonlinear viscoelastic behavior, DOI: 10.1177/0309324714554965. J Strain Analysis, v. 50, n. 1, pp. 4-14, 2015.

[11] COSTA, I., BARROS, J. Tensile creep of a structural epoxy adhesive: Experimental and analytical characterization, http://dx.doi.org/10.1016/j.ijadhadh.2015.02.006. International Journal of Adhesion \& Adhesives, v. 59, pp. 115-124, 2015.

[12] FENG, C.W., KEONG, C.W., HSUEH, Y.P., et al.. Modeling of long-term creep behavior of structural epoxy adhesives. Int J Adhes Aches, v. 25, n. 5, pp. 427-36, 2005.

[13] SAHELliE, S., PASTERNAK, H., Expectancy of the lifetime of bonded steel joints due to long-term shear loading, Arquives of civil and mechanical engineering, DOI: 10.1016/j.acme.2015.05.004. v 15i4, pp. 1061-1069, 2015.

[14] ZEHSAZ, M., TAHAMI, F.V., SADIGH, M.A.S., Creep analysis of adhesively bonded single lap joint using finite element method, DOI 10.1007/s12206-014-0508-5 Journal of Mechanical Science and Technology, v. 28, pp. 2743-2748, 2014.

[15] SADIGH, M.A.S., Creep simulation of adhesively bonded joints using modified generalized time hardening model, DOI 10.1007/s12206-016-0310-7Journal of Mechanical Science and Technology, v. 30, pp. 1555-1561, 2016.

[16] ISO 15109, Adhesives - Determination of the time to rupture of bonded joints under static loads, International Standard, Geneve, Switzerland, 1998.

[17] KHALILI, S.M.R., JAFARKARIMI, M.H., ABDOLLAHI, M.A., Creep analysis of fibre reinforced adhesives in single lap joints - Experimental study, DOI: 10.1016/j.ijadhadh.2009.02.007. International Journal of Adhesion \& Adhesive, v. 29, pp. 656-661, 2009. 
[18] MESHGIN, P., CHOI, K.K., TAHA, M.M.R., Experimental and analytical investigations of creep of epoxy adhesive at the concrete-FRP interfaces, DOI:10.1016/j.ijadhadh.2008.01.003. International Journal of Adhesion \& Adhesive, v. 29, pp. 56-66, 2009.

[19] HAN, X., CROCOMBE, A.D., ANWAR, S.N.R., et al., The strength prediction of adhesive single lap joints exposed to long term loading in a hostile environment, DOI: 10.1016/j.ijadhadh.2014.06.013. International Journal of Adhesion \& Adhesive, 2014.

[20] ASTM D1002-10, Standard Test Method for Apparent Shear Strength of Single-Lap-Joint Adhesively Bonded Metal Specimens by Tension Loading (Metal-to-Metal), ASTM International, West Conshohocken, PA, 2010.

[21] ISO 4288, Geometrical Product Specifications (GPS) - Surface texture: Profile method - Rules and procedures for the assessment of surface texture, 1996.

[22] DA SILVA, R.H., SAMPAIO, E.M., ROHEM, N.R., et al., Development of pipe repairs using bonded metal plate - Part I: Shape factor, stiffness and surface treatment, https://doi.org/10.1016/j.ijadhadh.2020.102594. International Journal of Adhesion and Adhesives, 100, 102594, 2020.

[23] ZUGLIANI, P.A., BANEA, M.D., BUDHE, S., et al., Bonded composite repair of metallic pipeline using energy release rate method, DOI: 10.1080/01694243.2019.1632537. Journal of Adhesion Science and Technology, 33:19, pp. 2141-2156, 2019.

\section{ORCID}

Ranulfo Martins Carneiro Neto

Mila Siqueira de Paula

Eduardo M. Sampaio

Ney Robson Ferreira Rohem

Lucas Lisbôa Vignoli
https://orcid.org/0000-0001-8260-960X

https://orcid.org/0000-0002-7000-2883

https://orcid.org/0000-0002-0339-0716

https://orcid.org/0000-0002-2982-421X

https://orcid.org/0000-0003-3288-3568 